OPEN ACCESS

Edited by:

Claude Alain,

Rotman Research Institute (RRI),

Canada

Reviewed by:

Sari Ylinen,

University of Helsinki, Finland

Eino Partanen,

University of Helsinki, Finland

*Correspondence:

Yan H. Yu

yuy1@stjohns.edu;

yanhyu@gmail.com

Specialty section

This article was submitted to

Auditory Cognitive Neuroscience,

a section of the journal

Frontiers in Psychology

Received: 19 October 2017

Accepted: 27 February 2018

Published: 22 March 2018

Citation:

Yu YH, Shafer VL and Sussman ES

(2018) The Duration of Auditory

Sensory Memory for Vowel Processing: Neurophysiological and Behavioral Measures.

Front. Psychol. 9:335.

doi: 10.3389/fpsyg.2018.00335

\section{The Duration of Auditory Sensory Memory for Vowel Processing: Neurophysiological and Behavioral Measures}

\author{
Yan H. Yu ${ }^{1 *}$, Valerie L. Shafer ${ }^{2}$ and Elyse S. Sussman ${ }^{3}$ \\ 1 Department of Communication Sciences and Disorders, St. John's University, Queens, NY, United States, ${ }^{2}$ Ph.D. Program \\ in Speech-Language-Hearing Sciences, The Graduate Center, The City University of New York, New York, NY, United States, \\ ${ }^{3}$ Dominick P. Purpura Department of Neuroscience, Albert Einstein College of Medicine, New York, NY, United States
}

Speech perception behavioral research suggests that rates of sensory memory decay are dependent on stimulus properties at more than one level (e.g., acoustic level, phonemic level). The neurophysiology of sensory memory decay rate has rarely been examined in the context of speech processing. In a lexical tone study, we showed that long-term memory representation of lexical tone slows the decay rate of sensory memory for these tones. Here, we tested the hypothesis that long-term memory representation of vowels slows the rate of auditory sensory memory decay in a similar way to that of lexical tone. Event-related potential (ERP) responses were recorded to Mandarin non-words contrasting the vowels /i/ vs. /u/ and /y/ vs. /u/ from first-language (L1) Mandarin and L1 American English participants under short and long interstimulus interval (ISI) conditions (short ISI: an average of 575 ms, long ISI: an average of $2675 \mathrm{~ms}$ ). Results revealed poorer discrimination of the vowel contrasts for English listeners than Mandarin listeners, but with different patterns for behavioral perception and neural discrimination. As predicted, English listeners showed the poorest discrimination and identification for the vowel contrast /y/ vs. /u/, and poorer performance in the long ISI condition. In contrast to Yu et al. (2017), however, we found no effect of ISI reflected in the neural responses, specifically the mismatch negativity (MMN), P3a and late negativity ERP amplitudes. We did see a language group effect, with Mandarin listeners generally showing larger MMN and English listeners showing larger P3a. The behavioral results revealed that native language experience plays a role in echoic sensory memory trace maintenance, but the failure to find an effect of ISI on the ERP results suggests that vowel and lexical tone memory traces decay at different rates.

\section{Highlights:}

We examined the interaction between auditory sensory memory decay and language experience.

We compared MMN, P3a, LN and behavioral responses in short vs. long interstimulus intervals. 
We found that different from lexical tone contrast, MMN, P3a, and LN changes to vowel contrasts are not influenced by lengthening the ISI to $2.6 \mathrm{~s}$.

We also found that the English listeners discriminated the non-native vowel contrast with lower accuracy under the long ISI condition.

Keywords: sensory memory decay, vowel processing, mismatch negativity, late negativity, event-related potentials, speech perception, interstimulus interval, P3a novelty

\section{INTRODUCTION}

Mismatch negativity (MMN) is an event-related brain potential (ERP) component that is elicited by a stimulus that is detected as a violation of automatic predictions of the central auditory system (Näätänen et al., 2011). MMN was traditionally interpreted in terms of echoic auditory sensory memory, which can last ca. $10 \mathrm{~s}$ as a result of repeating standard stimuli in the central auditory system (e.g., Näätänen et al., 1978; Cowan, 1984, 1988). The strength and durability of the echoic sensory memory trace, as reflected by the MMN, is affected by a number of factors, including the number of standard stimulus repetitions before the deviant (Sams et al., 1983; Imada et al., 1993; Javitt et al., 1998), the acoustic distinctiveness of the standard-deviant contrast (e.g., Sams et al., 1985), the linguistic status of the contrast (e.g., Näätänen et al., 1997), and the rate of stimulus presentation (e.g., Schröger, 1996; Sussman et al., 2008). More specifically, smaller MMN amplitude has been observed to a smaller magnitude of stimulus change in tone frequency, duration or intensity (e.g., Sams et al., 1985; Lang et al., 1990; Tiitinen et al., 1994; Amenedo and Escera, 2000; Rinne et al., 2006). Studies have also shown smaller or absent MMNs for non-native compared to native phonetic contrasts that are phonemic only for the native group (Dehaene-Lambertz, 1997; Näätänen et al., 1997; Sharma and Dorman, 1999; Winkler et al., 1999a). MMN also decreases in amplitude when the ISI between standard and deviant auditory stimuli is increased (Sams et al., 1993; Schröger, 1996; Čeponienè et al., 1998, 1999; Javitt et al., 1998; Gomes et al., 1999; Barry et al., 2008). Horváth et al. (2008a) argued that the amplitude of MMN varies little in the magnitude from trial to trial for a clearly discriminable difference; in contrast the smaller MMN amplitude to a just-noticeable difference may reflect that deviance detection occurs only for a subset of the trials.

Sensory memory decays in a non-linear fashion, but this decay rate is dependent on a number of factors. Behavioral speech perception research suggests that the rate of sensory memory decay is dependent on stimulus properties at more than one level. For example, at the acoustic level, a "simpler" (steadystate) vowel has an advantage over a "complex" (brief and transitional) consonant in terms of the rate of decay (Pisoni, 1973). At a phonemic level, a between-category but not withcategory consonant contrast that differs equally on an acoustic scale, can be retained for successful behavioral discrimination at a minimal ISI of $1.5 \mathrm{~s}$, and possibly at a much longer ISI than $1.5 \mathrm{~s}$. For example, Hindi participants had no difficulties discriminating the between-category Hindi sounds as different at an ISI of $1.5 \mathrm{~s}$ (Werker and Logan, 1985).

\section{Mismatch Negativity and ISI Modulation}

The interactions between sensory memory trace decay and auditory discrimination, as measured by the MMN responses, have been investigated using pure tones (e.g., Sams et al., 1993), consonant contrast (Čeponienè et al., 1999) and lexical tones (Yu et al., 2017). The accumulated evidence thus far suggests that the rate of sensory memory trace decay may differ depending on the nature of the stimulus. For example, Sams et al. (1993) found that in healthy young adults, MMN can be elicited with an ISI as long as $10 \mathrm{~s}$ when the stimuli are auditory pure tones that differ in frequency by $10 \%$. Čeponienè et al. (1999) found that two groups of 7-9 years old children with high and low phonological memory skills, as measured by nonword repetition (NWR), showed very similar MMN responses to auditory tone changes $(1000 \mathrm{~Hz}$ vs. $1100 \mathrm{~Hz})$ under both short $(350 \mathrm{~ms})$ and long (2000 ms) ISI conditions. However, the higher NWR repeaters differed from the lower NWR repeaters in terms of the MMN amplitude for a consonantal voicing contrast (/baga/-/baka/). The MMN amplitude was greatly reduced in high repeaters under the long ISI condition compared to that of the short ISI condition, and no MMN was observed for either the short or long ISI conditions in the low repeaters. In $\mathrm{Yu}$ et al. (2017), we found that native speakers of English failed to show an early negativity (i.e., MMN) to a Mandarin lexical tone contrast, which is phonemic in Mandarin but not English, when the ISI was greater than $2.5 \mathrm{~s}$; however, English listeners did show MMN to the lexical tone contrast under a short ISI of approximately $500 \mathrm{~ms}$. The Mandarin native listeners showed comparable MMNs for both the long and short ISI.

To our knowledge, there is no study that has directly examined the duration of the neuronal trace of auditory sensory memory for vowels. Recent evidence suggested that consonants, vowels and lexical tones are weighted differently (Wiener and Turnbull, 2016). In this paper, we examined whether the rate of sensory memory decay for vowels differs from the rate of decay for lexical tone reported in Yu et al. (2017).

\section{P3a and ISI Modulation}

The P3a component (sometimes called novelty P3), a frontalcentral positivity, is often considered to be a correlate of involuntary attention switch in a passive listening paradigm (e.g., Squires et al., 1975; Polich, 1988, 2007; Escera et al., 1998; Friedman et al., 2001 for reviews). Both the magnitude of stimulus deviance and the probability of the deviant occurrence affect the peak amplitude of P3a. Larger magnitude of stimulus deviance and lower probability of the deviant lead to a larger P3a peak amplitude (e.g., Schröger and Wolff, 1998a,b; Winkler et al., 
1998; Escera et al., 2001; Yago et al., 2001). Sussman et al. (2003) found that P3a was present when the deviant was unpredictable and absent when the deviant was predictable, suggesting that P3a represents an involuntary orienting of attention to an unexpected sound (Sussman et al., 2003). Larger P3a amplitudes evoked by non-native contrasts compared to native contrasts have been observed (e.g., Shestakova et al., 2003) and late bilingual learners have larger P3a amplitudes than early bilingual learners (OrtizMantilla et al., 2010). Few studies have examined how ISI modulates the P3a responses. The question of whether P3a is sensitive to ISI modulation has yet to be established. In a recent systematic review by Bartha-Doering et al. (2015), out of 37 MMN studies that have ISI manipulation, there was only one study that also discussed P3a responses (Czigler et al., 1992). Czigler et al. (1992) reported an unexpected P3a component in young adults (age $=21.3$ years, $n=8$ ) when the ISIs were 800 and $2400 \mathrm{~ms}$, but the P3a was absent in the same participants when the ISI was longer (up to $7200 \mathrm{~ms}$ ). Furthermore, no P3a was observed in healthy older adults (age $=60.8, N=8$ ).

\section{Late Negativity and ISI Modulation}

In a passive oddball paradigm, following $\mathrm{MMN}$ and $\mathrm{P} 3 \mathrm{a}$, a frontocentral late negativity (LN) is often generated. The LN is considered an index of re-orienting to the stimulus change, similar to the re-orienting negativity (RON) reported in Schröger and Wolff (1998a) (see Escera et al., 2000 for a review). The LN has been less frequently reported, but an increasing number of studies suggest that it is a fairly common mismatch response (Korpilahti et al., 2001; Shestakova et al., 2003; Shafer et al., 2005; Kaan et al., 2007; Barry et al., 2009; Bishop et al., 2010; Datta et al., 2010; Ortiz-Mantilla et al., 2010; Choudhury et al., 2015). The question of how language experience modulates LN responses has not been systematically explored. Some studies reported larger LN amplitude in higher language performers (e.g., Barry et al., 2009), while others reported the opposite results. Several studies observed that $\mathrm{LN}$ is larger to speech contrasts in second language learners (e.g., Ortiz-Mantilla et al., 2010), or in other clinical groups (e.g., Addis et al., 2010). Shafer et al. (2005) observed an LN of comparable amplitude in children with specific language impairment (SLI) and age-matched controls with typical language.

Late negativity amplitude and latency are also found to interact with the salience of an acoustic contrast, the rate of presentation and with attention (e.g., Choudhury et al., 2015). Choudhury et al. (2015) have found that attending to a very fastrate stimulus contrast (an ISI of 10 or $70 \mathrm{~ms}$ ) led to larger LN amplitude compared to a slow-rate stimulus. In the lexical tone study, we found larger LN amplitudes in the native Mandarin listeners than in the English listeners for Mandarin lexical tone contrasts (Yu et al., 2017). The amplitude of LN in the Mandarin listeners was either the same or larger in the long ISI condition compared to the short ISI condition. It currently is unclear whether LN is actually a second MMN, or rather a separate component. In addition, very few studies have examined how memory trace decay affects LN (Yu et al., 2017). Thus, further research is necessary to elucidate the nature of the $\mathrm{LN}$, and how ISI modulates the LN responses.

\section{The Role of Long-Term Memory in Non-native Speech Processing}

For the purpose of this study, we define long-term memory as the established mental representation of phonemic categories of native language experience. It is well established that the amplitude of MMN to native language phonemic contrasts is larger than for non-native speech contrasts that are nonphonemic in the listener's native language (Dehaene-Lambertz, 1997; Näätänen et al., 1997; Sharma and Dorman, 1999; Winkler et al., 1999a). Speech perception models, such as the perceptual assimilation model (PAM) posited that the first language (L1) system constrains the perception of non-native speech sounds that are unfamiliar to the listener (Best, 1995; Best and Tyler, 2007). A postulate of PAM is that naïve listeners perceptually assimilate a non-native phone to the native phoneme that is the closest articulatory match, if the listeners can find a match (good or poor) in their L1 (Best and Tyler, 2007).

Mandarin has six primary vowels (excluding diphthongs). These include high-front /i/ and high-back /u/ vowels that are similar to English (Howie, 1976; Lee and Zee, 2003) and high, front-rounded vowel /y/. English, in contrast, has more vowel distinctions (11 excluding diphthongs), but does not include the front-rounded vowel /y/. Furthermore, English includes the constraint on back vowels that they are all round (+round feature), whereas front vowels are non-round (-round). Thus, PAM predicts that English listeners will assimilate the Mandarin /y/ into the most similar category, and given the constraint on English front vowels lacking the feature "round," English /u/ (high, and round) should be closest match.

The one study that has tested behavioral discrimination of Mandarin /y/ vs. /u/ by naïve English speaker revealed that the difference can be discriminated well-above-chance (mean 92\% correct) (Hao, 2017). This study used an AXB task (with $1 \mathrm{~s}$ between three-syllable phrases) rather than identification and did not compare performance to Mandarin listeners. In a different study examining identification of the French front-rounded /y/ vs. back-rounded /u/, English listeners categorized /y/ in a single category with /u/ (Levy and Strange, 2008).

According to PAM and the findings regarding French $/ y /$, English listeners are expected to show poorer discrimination of Mandarin / $/$ / and / $\mathrm{u} /$ than Mandarin listeners, assimilating these into one category [called "single-category (SC) assimilation in PAM]. The Hao (2017) study, however, suggests that English listeners will show evidence of good discrimination. With regards to Mandarin /u/ vs. /i/, English listeners are expected to assimilate these into two separate categories [called two category (TC) assimilation in PAM] that correspond to English /u/ and English /i/. Thus, higher behavioral discrimination and identification accuracy is expected for /u/ vs. /i/ than for Mandarin /y/ vs. /u/.

\section{Objectives of This Study}

We investigated whether the interstimulus rate (ISI) influenced neural responses to infrequent vowel changes and to what extent this was modulated by language experience. A second aim was to determine whether vowel processing and lexical tone processing differ at the neural level in terms of sensory memory decay. 
Answers to these questions are of interest for theoretical, as well as for practical reasons. With regards to language experience, it is important to know whether different phonological properties (vowel, consonant, and lexical tone) show different decay rates in relation to experience. In addition, these results will allow us to estimate the potential of using sensory memory decay as a reliable means for assessing implicit cognitive informationprocessing capabilities in applied/clinical testing situations. A recent systematic review of how ISI modulates the amplitude of MMN revealed that factors, such as maturation and normal aging influence the duration of sensory memory (Bartha-Doering et al., 2015). However, the studies reviewed in Bartha-Doering et al. (2015) are oddball paradigms using pure tones as stimuli. Few studies have directly compared the rate of sensory memory decay for different types of linguistic stimuli (e.g., vowel, consonant, and lexical tone) (e.g., consonant: Čeponienè et al., 1999; lexical tone: Yu et al., 2017). The question remains open as to whether the type of stimuli interact with the rate of sensory memory decay. This study focuses on vowel contrasts, which we can then compare to our previous study of lexical tone ( $\mathrm{Yu}$ et al., 2017).

The current study focuses on the modulation of MMN, P3a and LN under different ISI conditions for two vowel contrasts, one of which is phonemic $(/ \mathrm{i} /-/ \mathrm{u} /)$ for both English and Mandarin listeners, and a second $(/ \mathrm{y} /-/ \mathrm{u} /)$ which is phonemic only for Mandarin listeners. We used an average ISI of $575 \mathrm{~ms}$ (range 545-609 ms) for the short ISI condition and an average ISI of $2675 \mathrm{~ms}$, (range of 2645-2709 ms) for the long ISI condition (see Yu et al., 2017 for details). We hypothesized that native language experience would interact with the rate of memory trace decay. The two language groups would show larger dissimilarity in the behavioral and ERP responses for the long ISI compared to the short ISI. This is because when the ISI is short, listeners can rely on the acoustic-phonetic cues for discrimination of non-native speech contrast while with a long ISI, the detailed acoustic-phonetic cues would not be available, and speech processing has to rely on the long-term memory representation. Thus, behavioral perception and the MMN brain discriminative response would be poorer at the long vs. the short ISIs and poorer for English than Mandarin listeners for the /y/ vs. /u/ contrast.

\section{MATERIALS AND METHODS}

\section{Participants}

We tested 68 adult participants between the age of 20 and 42 years of age using a between-subject design. Data from a total of five participants (two from the English short ISI group, two from the Mandarin short ISI group, and one from the Mandarin long ISI group) were excluded from the analysis due to incomplete participation $(N=2)$, or excessive noise in the data defined by retaining less than $50 \%$ of trials after artifact reject $(N=2)$ or no clear obligatory components $(N=1)$. Therefore, a total of 63 adult participants were included in the analyses. There were 15 participants in the English long ISI group (8 males, 7 females), 16 participants in the English short ISI group (7 males, 9 females), 16 (9 males, 7 females) in the Mandarin long ISI group and 16 ( 8 males, 8 females) in the Mandarin short ISI group. The 31 native speakers of English (16 in the short ISI and 15 in the long ISI condition, age range: $20-42$ years) had little or no exposure to any tone languages. The 32 native speakers of Mandarin (16 participants in each ISI condition, age range: 21-40 years) were all from Mainland China, and all moved to the United States no earlier than during their high school years. Participants' age, gender, music training and handedness were controlled across language/ISI groups. These were the same participants as in Yu et al. (2017). The study was approved by The Graduate Center, CUNY Institutional Review Board, and was conducted in compliance with the Declaration of Helsinki. All the participants signed the informed consent. All the participants were recruited from the metropolitan New York City area via flyers and Craigslist, and were paid $\$ 10$ per hour.

\section{Stimuli}

The stimuli were produced in Mandarin by a bilingual MandarinEnglish female speaker, for whom Mandarin was the first language (lived in China until 20 years of age). They were recorded using Sound Forge 4.5 at the sampling rate of 22,050 Hz. A total of 11 tokens of stimuli were selected from a large set of stimuli after batch normalization using average RMS normalization function in Sound Forge 8.1 and detailed acoustic analyses using Praat (Boersma, 2001). Among these 11 tokens, three were for the standard "gupa" condition (with "gu" in Mandarin Tone 3, a low rising fundamental frequency contour) and two were for each of the four deviant stimulus types. The two vowel deviants were "gipa" and "gypa", both with Tone 3 on the first syllables, and the two lexical tone deviants were "gupa" with a rising tone (Tone 2 ) on the first syllable, and "gupa" with a high level tone (Tone 1 ) on the first syllable. The second syllable "pa" was always produced with Tone 1 (see Table $\mathbf{1}$ for acoustic details). To verify the validity of the stimuli, before we launched the experiment, four native Mandarin adult listeners (one Ph.D. student in speech and hearing, two journalists, and one manager) judged that all the stimuli were native-sounding Mandarin speech. The rationale for using more complex stimuli and multiple deviant conditions was to increase the ecological validity of the task and to enhance the possibility of participants relying on phonological processing instead of phonetic processing. In this paper, we focus on the vowel differences.

\section{Paradigm}

Participants were seated in a sound-attenuated and electrically shielded booth for a passive listening MMN paradigm and behavioral tasks. E-Prime software (Psychology Software Tools, Pittsburgh, PA, United States) was used for stimulus presentation and behavioral data collection. A 65-channel Geodesic sensor net was used for ERP data collection.

One block consisted of 103 pseudo-randomly presented stimuli, and a total of twenty blocks were presented with an interblock interval of $20 \mathrm{~s}$. The vowel and lexical tone deviant stimuli were interspersed within the sound stream of common standard stimulus type /gu3pa/. Figure 1 provides examples of 
TABLE 1 | Characteristics of the experimental stimuli.

\begin{tabular}{|c|c|c|c|c|c|c|c|}
\hline \multirow[t]{2}{*}{ Stimuli } & \multicolumn{2}{|c|}{ /gipa/ } & \multicolumn{2}{|c|}{ /gypa/ } & \multicolumn{3}{|c|}{ /gupa/ } \\
\hline & Token 1 & Token 2 & Token 1 & Token 2 & Token 1 & Token 2 & Token 3 \\
\hline $\mathrm{FO}-\mathrm{gV}(\mathrm{Hz})$ & 153 & 155 & 138 & 142 & 140 & 142 & 143 \\
\hline FO-pa (Hz) & 174 & 173 & 166 & 185 & 167 & 168 & 171 \\
\hline Duration:overall (ms) & 314 & 336 & 342 & 355 & 320 & 326 & 346 \\
\hline Voice onset time /g/ & 34 & 24 & 16 & 36 & 21 & 22 & 23 \\
\hline Duration:gV(ms) & 114 & 113 & 129 & 157 & 132 & 139 & 134 \\
\hline Duration: pa (ms) & 200 & 223 & 213 & 198 & 188 & 187 & 212 \\
\hline Intensity:overall (dB) & 71.4 & 67.9 & 66.8 & 68.1 & 68.8 & 70.9 & 70.8 \\
\hline Intensity:gV (dB) & 70.8 & 72.1 & 62.6 & 66.9 & 69.3 & 70.6 & 71.6 \\
\hline Intensity:pa (dB) & 71.8 & 66 & 68.8 & 68.9 & 68.4 & 71.1 & 70.4 \\
\hline \multicolumn{8}{|l|}{ Formant Frequency } \\
\hline $\mathrm{F} 1: \mathrm{gV}(\mathrm{Hz})$ & 330 & 328 & 306 & 327 & 345 & 345 & 341 \\
\hline $\mathrm{F} 2: \mathrm{gV}(\mathrm{Hz})$ & 2437 & 2298 & 1626 & 1792 & 1013 & 1102 & 1154 \\
\hline F3:gV (Hz) & 2980 & 2635 & 2360 & 2330 & 2622 & 2630 & 2688 \\
\hline F1:pa (Hz) & 686 & 691 & 659 & 715 & 722 & 766 & 778 \\
\hline F2:pa (Hz) & 1601 & 1544 & 1595 & 1399 & 1538 & 1465 & 1478 \\
\hline F3:pa (Hz) & 3065 & 2912 & 3062 & 2999 & 2681 & 2648 & 2730 \\
\hline
\end{tabular}

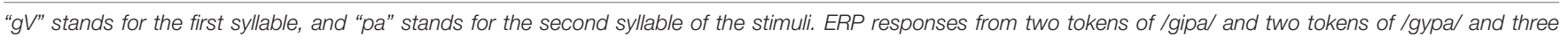
tokens of /gupa/ were included in the analyses.

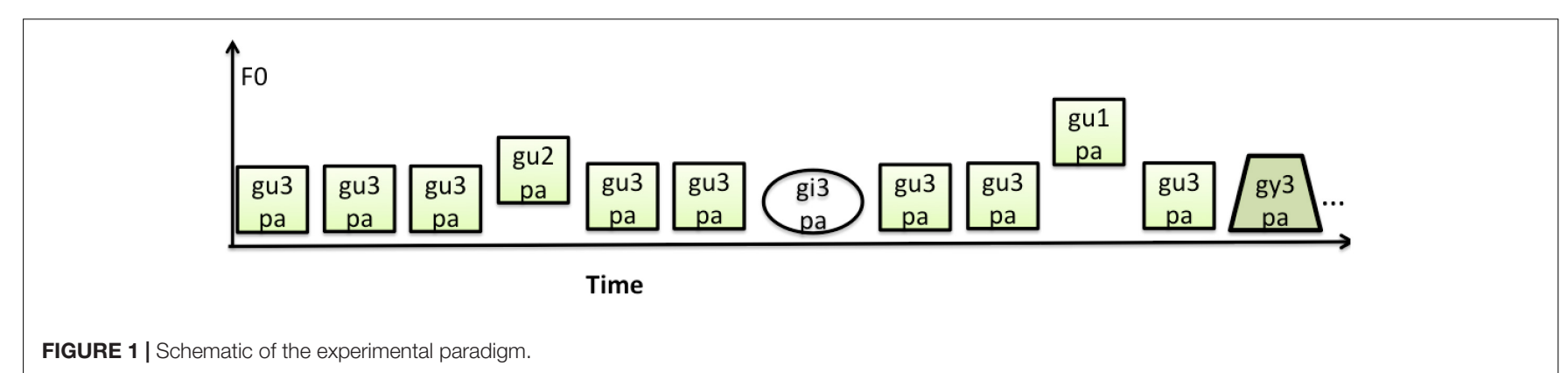

the stimulus sequences used in the study. A total of 200 deviant trials per category with a probability of $9.7 \%$ and a total of 1260 standard stimuli with a probability of $62.2 \%$ were presented. The standard stimuli that were at the beginning of the list, or following a deviant of any type, were excluded from the analyses. A total of 440 trials of standard stimuli were included in the offline ERP analyses. The /gupa/ with a different tone were not included in the analysis as they had a dual role of serving as the vowel standard and lexical tone deviant in the experiment.

A behavioral discrimination task for the vowels (four standard and a fifth/final deviant) followed the ERP measurement. No EEG activity was recorded during the behavioral testing. Participants were asked to determine whether the stimulus in the final position of the sequence of five stimuli was the same or different from the previous four stimuli. The ISI between stimuli was the same as for the ERP paradigm, that is, short ISI for participants receiving the short ISI ERP condition and long ISI for those receiving the long ISI ERP condition. A three-alternative forced choice identification task with "gipa," "gupa," or "gypa" as the alternatives was presented last. Each participant received six practice trials plus 30 test trials, and each was asked to press button " 1 " for "gipa," button " 2 " for "gupa," and button " 3 " for "gypa." The purpose of this task was to determine the category perception.

We also included a post-study test to evaluate how well each vowel stimulus matched the English /i/ and / $\mathrm{u} /$ categories. Fourteen native English undergraduate students were asked to report which vowel they heard in the first syllable of "gVpa," then using a 5-point Likert scale to judge how English-sounding each token of "gVpa" was ("1" = native English sounding, "3" somewhat English sounding, " $5 "=$ not English sounding at all). Nine out of 14 listeners identified the two tokens of "gipa" as English "gipa," and 10 of 14 listeners identified the three tokens of "gupa” as English "gupa." Twelve out of 14 listeners judged the first token of "gypa" as "gupa," and all 14 listeners judged the second token of "gypa" as "gupa." The English-sounding ratings for the two tokens of "gipa" were 2.6 and 2.8. The three tokens of "gupa" received the ratings of 2.9, 3.0, and 3.2, and the two tokens of "gypa" were rated as 3.56 and 3.50. Thus, the majority of the listeners consistently identified the Mandarin /i/ and /u/ tokens 
as best matching with English /i/ and /u/, respectively, whereas both Mandarin /y/ tokens were placed with English /u/.

All stimuli were presented free-field with a comfortable listening level of $70.2 \mathrm{~dB}(S D=1.9 \mathrm{~dB})$. The ISI between stimuli ranged from 545 to $609 \mathrm{~ms}$ (stimulus onset asynchrony, $\mathrm{SOA}=900 \mathrm{~ms}$ ) for the short ISI condition and 2645-2709 ms $(\mathrm{SOA}=3000 \mathrm{~m})$ for the long ISI condition. The entire experiment lasted $2-2.5 \mathrm{~h}$ for the short ISI experiment, and 3-3.5 $\mathrm{h}$ for the long ISI experiment. Breaks were given halfway through the ERP experiment and whenever the participant requested.

\section{ERP Recording and Offline Processing}

The continuous EEG was time-locked to the onset of the stimuli. The EEG was recorded with a band pass of $0.1-100 \mathrm{~Hz}$, and a sampling rate of $500 \mathrm{~Hz}$ from 64 scalp sites using a Geodesic sensor net with the vertex electrode $(\mathrm{Cz})$ as the reference. For offline processing, the EEG was refiltered using a finite impulse response (FIR) band-pass filter of $0.3-15 \mathrm{~Hz}$, and was segmented into $1000 \mathrm{~ms}$ epochs, including a $200 \mathrm{~ms}$ pre-stimulus baseline. Eye movement artifacts were removed using automatic EOG artifact and eye movement artifact correction via Brain Electrical Source Analyses (BESA) (BESA research 5.2, BESA GmbH, Germany). Epochs that exceeded the amplitude threshold of $120 \mu \mathrm{V}$ were excluded. After artifact removal, on average, 178.4 trials $(89 \%$; $S D=15.7)$ for the /gipa/ deviant condition, 177.8 trials $(89 \% ; S D=16.8)$ for the /gypa/ deviant condition and $408.3(92 \%, S D=35.8)$ trials for the /gupa/ standard condition were included in each individual average. Bad channels were interpolated using the BESA spline interpolation method. The data were re-referenced using the average of all 65 sites and baseline corrected.

\section{DATA ANALYSIS}

\section{"Composite" FzCz Measures}

To reduce inter-subject variation in the topography of the ERP to speech (Zevin et al., 2010), and to reduce the contribution of independent noise sources at each electrode site to the signal of interest, we built a model of frontocentral activity from six sites around $\mathrm{Fz}$ and $\mathrm{Cz}$ as follows. We chose $\mathrm{Fz}$ and $\mathrm{Cz}$ as pivotal sites because $\mathrm{MMN}$ is known to have a frontocentral topography, and visual inspection of the data shows that $\mathrm{Fz}$ and $\mathrm{Cz}$ do indeed have the consistently largest MMN amplitude across participants. We then selected four sites that had the highest average correlation across conditions with $\mathrm{Fz}$ and $\mathrm{Cz}$ (mean Pearson's correlation coefficients $=0.92, S D=0.06$ ). Thus, the six sites used in the model were Fz/4, 5, 9, 55, 58, and $\mathrm{Cz} / 65$. The average responses from these six sites were treated as one electrode " $\mathrm{FzCz}$ composite," and were used for subsequent statistical analyses. The electrode placement is shown in Figure 2.

\section{ERP Analyses}

The subtraction waves were derived by subtracting the ERP waveform evoked by the standard stimuli from the ERP evoked by the deviant stimuli. We downsampled the data from the recording sampling rate of $500-25 \mathrm{~Hz}$ using appropriate smoothing to preclude aliasing in Igor Pro, 2017 (Wavemetrics). After downsampling, each data point represented the amplitude for a 40-ms time window. Visual examination of the individual and group average data indicates that the time range for MMN is between 80 and $240 \mathrm{~ms}$, with the /gipa/ deviant showing earlier amplitude peak than the /gypa/ deviant condition. The time range for P3a was between 160 and $360 \mathrm{~ms}$, and the time range for LN was between 340 and $500 \mathrm{~ms}$. We identified the maximal amplitude from the downsampled individual waveforms (the most negative value among the four intervals of 40-ms time windows for MMN and LN, and the most positive value among the five intervals of 40-ms for P3a) from each participant for each component. To examine the presence and absence of MMN, P3a, and LN, we conducted one-sample $t$-tests (onetailed) to examine whether the maximal amplitude in the 40-ms interval for MMN, P3a, and LN were significantly different from zero.

In a second set of analyses designed to test the language group, ISI condition and deviant type differences in the time range of interest, we used the maximal amplitude of the subtraction waveforms as described above in mixed model ANOVAs with language group (English and Mandarin) and ISI (short and long) as the between-group variable, and deviant stimulus type (gipa and gypa) as the within-group independent invariable.

\section{Behavioral Analysis}

For both the discrimination and identification task, we applied mixed model ANOVAs using language and ISI as the betweengroup variable, and vowel type as within-subject variable. The response accuracy was the dependent variable.

The Greenhouse-Geisser correction was applied whenever the degree of freedom in the denominator was larger than one. Uncorrected degrees of freedom, corrected $p$-values and generalized eta-squared $\left(\eta_{\mathrm{G}}^{2}\right)$ effect size were reported (Olejnik and Algina, 2003). Two-way interactions were examined using Tukeys' HSD post hoc tests, and Bonferroni correction used for multiple comparisons. All the analyses were conducted using $\mathrm{R}$ (R Core Team, 2016) and the nlme package (version 3.1-128) (RStudio Team, 2016; Pinheiro et al., 2017).

\section{RESULTS}

\section{ERP Results}

Figure 2 displays the grand mean ERPs to the standard and deviant stimuli waveforms for the composite $\mathrm{FzCz}$ site. Figure 3 shows the difference waveforms (waveforms from the deviant ERP minus the standard ERP).

\section{Presence/Absence of MMN, P3a, and LN}

One sample $t$-tests on individual language/ISI groups for each deviant condition showed that the amplitude of MMN for the 40 -ms interval that contained the peak was significantly more negative than zero $(p s<0.01)$ for all language/ISI groups under both deviant conditions. In other words, MMN was present in all language/ISI groups. P3a was present for both groups 


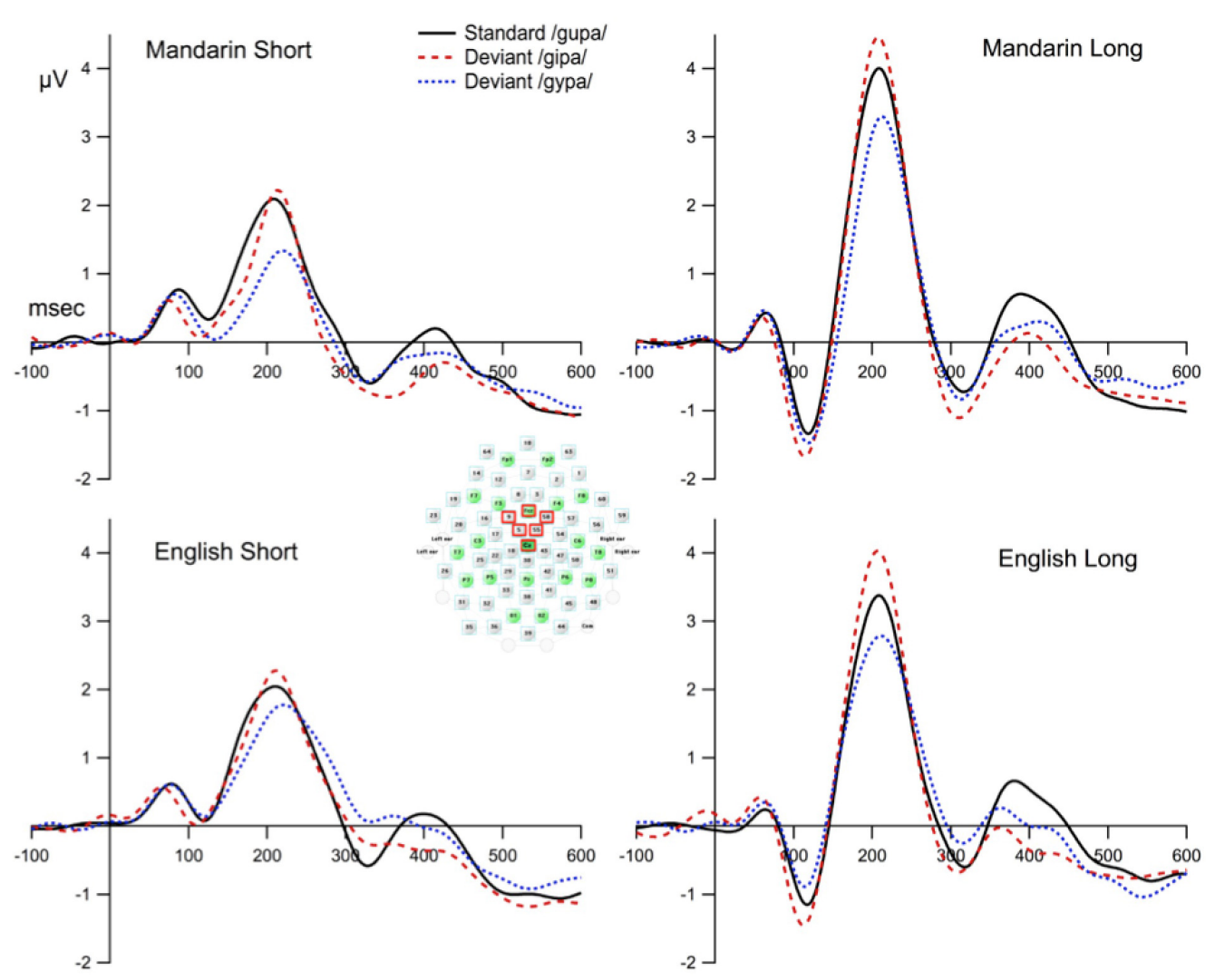

FIGURE 2 | The waveforms at the composite FzCz site for the standard and deviant stimulus condition. The composite FzCz site was generated using the average of six sites near FzCz (these sites are marked with red squares).
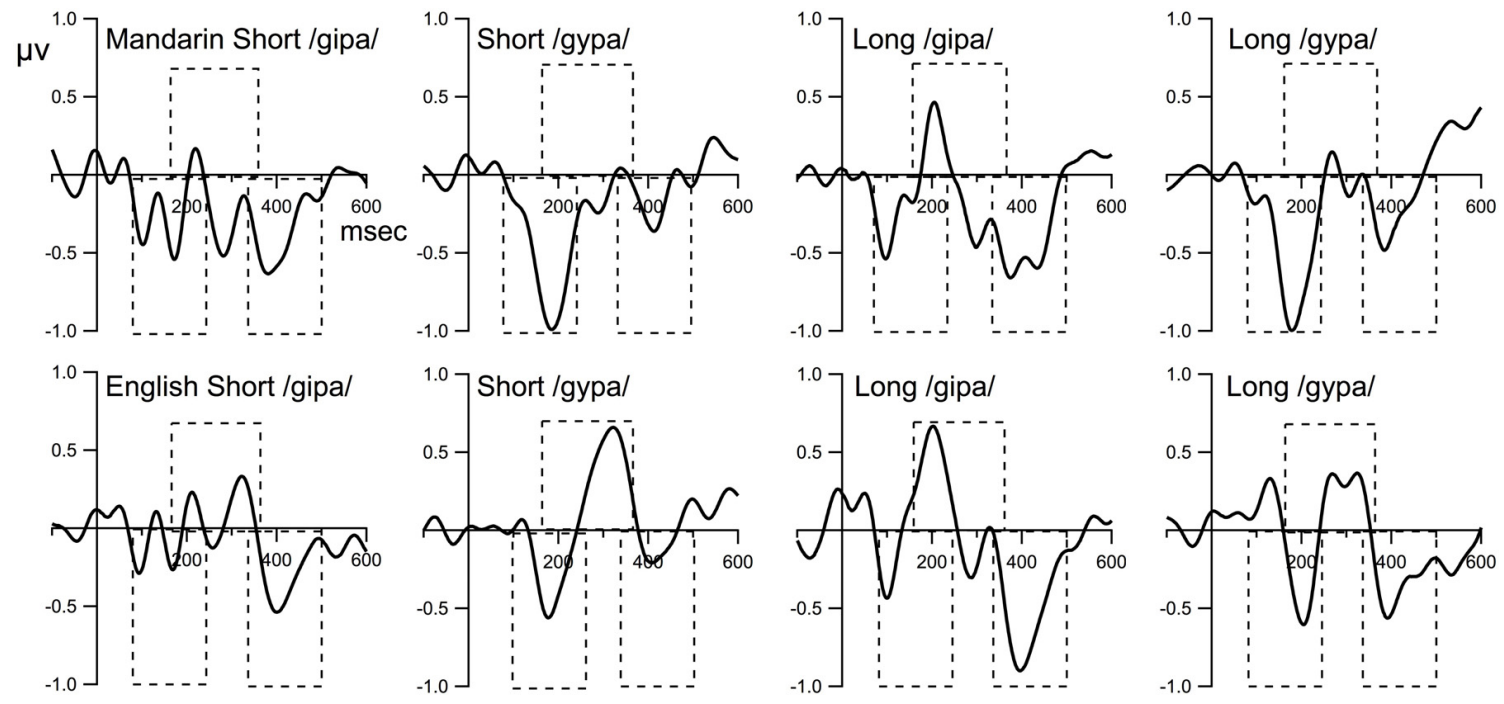

FIGURE 3| The difference waveforms (deviant minus standard). The time windows for MMN, P3a, and LN are 80-240 ms, 160-360 ms, and 340-500 ms, respectively. Dashed boxes indicate time window used for statistical analysis.

and both deviant conditions, except for the Mandarin short ISI group; specifically P3a was absent for the /gipa/ and the /gypa/ condition for the Mandarin short ISI group. LN was present in all conditions but the English short ISI group for the /gypa/ deviant condition. See Table 2 for the amplitudes and results from the $t$-tests for each component. 
TABLE 2 | Means (SD) of the average amplitude for the peak 40-ms interval and $t$-test (one-tailed) results of MMN, P3a and LN components for the four language/ISI groups under /gipa/ deviant and /gypa/ deviant conditions.

\begin{tabular}{|c|c|c|c|c|c|c|c|}
\hline & \multirow[b]{2}{*}{$\mathbf{N}$} & \multicolumn{2}{|c|}{ MMN } & \multicolumn{2}{|c|}{ P3a } & \multicolumn{2}{|c|}{ LN } \\
\hline & & Amplitude $(\mu \mathrm{V})$ & $t$-value & Amplitude $(\mu V)$ & $t$-value & Amplitude $(\mu \mathrm{V})$ & $t$-value \\
\hline \multicolumn{8}{|c|}{ Deviant = /gipa/ } \\
\hline Mand Short & 16 & $-0.70(0.46)^{* * *}$ & -6.11 & $0.18(0.61)$ n.s. & 1.27 & $-0.85(0.42)^{* * *}$ & -8.08 \\
\hline Mand Long & 16 & $-0.65(0.47)^{* * *}$ & -5.53 & $0.65(0.64)^{* *}$ & 2.79 & $-0.87(0.81)^{* * *}$ & -4.32 \\
\hline Eng Short & 16 & $-0.63(0.55)^{* * *}$ & -4.6 & $0.60(0.61)^{* * *}$ & 4.86 & $-0.62(0.45)^{* * *}$ & -5.51 \\
\hline Eng Long & 15 & $-0.45(0.47)^{* *}$ & -3.74 & $0.88(0.74)^{* * *}$ & 5.06 & $-0.99(0.54)^{* * *}$ & -7.04 \\
\hline \multicolumn{8}{|c|}{ Deviant = /gypa/ } \\
\hline Mand Short & 16 & $-1.09(0.62)^{* * *}$ & -6.99 & $0.13(0.61)$ n.s. & 0.90 & $-0.45(0.66)^{* *}$ & -2.75 \\
\hline Mand Long & 16 & $-1.03(0.62)^{* * *}$ & -6.60 & $0.38(0.64)^{*}$ & 2.37 & $-0.54(0.87)^{* *}$ & -2.51 \\
\hline Eng Short & 16 & $-0.67(0.43)^{* * *}$ & -6.22 & $0.76(0.61)^{* * *}$ & 4.93 & $-0.24(0.56)^{*}$ & -1.73 \\
\hline Eng Long & 15 & $-0.60(0.63)^{* * *}$ & -3.67 & $0.59(0.74)^{* *}$ & 3.06 & $-0.62(0.64)^{* * *}$ & -3.72 \\
\hline
\end{tabular}

"Mand Long", Mandarin long ISI condition; "Mand Short", Mandarin short ISI condition; "Eng Long", English Long ISI condition; "Eng Short", English short ISI condition. ${ }^{* * *} p \leq 0.001,{ }^{* *} p \leq 0.01,{ }^{*} p \leq 0.05,{ }^{n . s} p$-value is not significant.

\section{Language, ISI and Deviant Type Effect on the Amplitude of the Mismatch Negativity}

Mixed model ANOVA on MMN amplitude showed a main effect of language $\left[F(1,59)=6.138, p=0.02, \eta_{\mathrm{G}}^{2}=0.07\right]$ with Mandarin showing larger MMN than the English groups, a main effect of stimulus $\left[F(1,59)=9.99, p=0.002, \eta_{\mathrm{G}}^{2}=0.05\right]$ with the MMN amplitude for /gypa/ larger than that for /gipa/. No effect of ISI or interactions with ISI were observed. An interaction of language by stimulus $\left[F(1.59)=3.697, p=0.06, \eta_{\mathrm{G}}^{2}=0.02\right]$ approached significance. We had specifically predicted that English speakers would show poorer discrimination for /gypa/ vs. /gupa/ than for /gipa/ vs. /gupa/, and, thus, followed this with post hoc tests. These revealed that the two language groups differed significantly only in the /gypa/ condition with larger MMN for the Mandarin than for the English /gypa/ deviant condition (/gipa/ condition: English mean $=-0.54$, Mandarin mean $=-0.67, t=1.066$, $\mathrm{df}=59.8, p=0.29 ;(/ \mathrm{gypa} /$ condition: English mean $=-0.63$, Mandarin mean $=-1.06, t=2.936, \mathrm{df}=60.2, p=0.005)$.

\section{Language, ISI and Deviant Type Effect on the Peak Amplitude of the P3a Responses}

The results of mixed model ANOVA revealed a significant main effect of language $\left[F(1,59)=7.620, p<0.01, \eta_{G}^{2}=0.07\right]$ with the English participants showing larger P3a amplitudes. No other main effects or interactions were significant.

\section{Language, ISI and Deviant Type Effect on the Amplitude of the Late Negativity (LN)}

A mixed model ANOVA on LN amplitude revealed that the only statistical significance was for stimulus $[F(1,59)=19.5, p<0.001$, $\eta_{\mathrm{G}}^{2}=0.08$ ], with larger LN to /gipa/ than to /gypa/. No main effects or interactions involved language or ISI.

\section{Behavioral Discrimination Results}

The results for the mixed model ANOVA revealed a main effect of language $\left[F(1,59)=15.9, p<0.001, \eta_{G}^{2}=0.16\right]$ with Mandarin listeners performing better, a main effect of ISI $\left[F(1,59)=16.5, p<0.001, \eta_{\mathrm{G}}^{2}=0.16\right]$ with overall higher performance in the short ISI conditions, and a main effect of stimulus condition $\left[F(1,59)=77.5, p<0.001, \eta_{\mathrm{G}}^{2}=0.29\right]$ with higher performance in the /gipa/ deviant condition than in the /gypa/ deviant condition. Significant interactions included language by ISI $\left[F(1,59)=8.42, p<0.01, \eta_{\mathrm{G}}^{2}=0.09\right]$, language by stimulus condition $\left[F(1,59)=54.7, p<0.001, \eta_{\mathrm{G}}^{2}=0.22\right]$, ISI by stimulus condition $\left[F(1,59)=12.5, p<0.001, \eta_{\mathrm{G}}^{2}=0.06\right]$, and a three-way interaction of language by ISI by stimulus condition $\left[F(2,118)=16.8, p<0.001, \eta_{\mathrm{G}}^{2}=0.08\right]$. Post hoc tests found that there was no ISI effect in the Mandarin groups; but for the English listeners, the discrimination accuracy was higher in the short than the long ISI condition. Likewise, the Mandarin listeners performed with similar accuracy under /gupa/-/gipa/ and /gupa/-/gypa/ conditions, but the English listeners had lower accuracy in the /gypa/-/gupa/ condition than in the /gipa/-/gupa/ condition. Under the /gupa/-/gipa/ condition, accuracy in the long ISI condition did not differ from accuracy in the short ISI condition, but under the /gupa/-/gypa/ condition, accuracy in the long ISI was lower than in the short ISI condition. See Table 3 for details.

\section{Behavioral Identification Results}

All groups labeled each category as intended, which was wellabove chance level ( $>33.3 \%$, see Table 3$)$. Results from repeated model ANOVA revealed a main effect of language $[F(1,59)=30.3$, $\left.p<0.001, \eta_{\mathrm{G}}^{2}=0.19\right]$ with Mandarin listeners showing higher accuracy. In addition there was a main effect of stimulus $\left[F(2,118)=21.4, p<0.001, \eta_{\mathrm{G}}^{2}=0.17\right]$. Post hoc tests suggested that the accuracy for both /gipa/ and /gypa/ tokens were significantly lower than for /gupa/ tokens $(p s<0.001)$, and /gypa/ was lower than /gipa/ $(p=0.02)$. A language by condition interaction was also significant $[F(2,118)=7.16, p=0.001$, $\left.\eta_{\mathrm{G}}^{2}=0.06\right]$, and post hoc tests showed that for participants with an English background, /gypa/ was identified with significantly lower accuracy than /gipa/ $(p<0.001)$. However, for Mandarin participants, the accuracy for /gypa/ did not differ from that of /gipa/ $(p=0.86)$. ISI was not a significant factor for identification accuracy. 
TABLE 3 | Means (SD) of vowel discrimination accuracy and vowel identification under four language/interstimulus (ISI) groups.

\begin{tabular}{|c|c|c|c|c|c|}
\hline & \multicolumn{2}{|c|}{ Discrimination } & \multicolumn{3}{|c|}{ Identification } \\
\hline & /gipa/-/gupa/ & /gypa/-/gupa/ & /gipa/ & /gypa/ & /gupa/ \\
\hline Long ISI & $0.89(0.31)$ & $0.475(0.50)$ & $0.68(0.32)$ & $0.5(0.32)$ & $0.84(0.26)$ \\
\hline Short ISI & $0.98(0.15)$ & $0.80(0.40)$ & $0.67(0.17)$ & $0.52(0.31)$ & $0.84(0.23)$ \\
\hline Mandarin & $0.93(0.25)$ & $0.89(0.31)$ & $0.85(0.14)$ & $0.85(0.24)$ & $0.96(0.13)$ \\
\hline
\end{tabular}

The standard is /gupa/, and the deviants are /gipa/ and /gypa/.

\section{DISCUSSION}

The aims of this study were to examine how ISI influenced neural responses to infrequent vowel changes, and to what extent language experience modulates the ability to detect speech contrasts. Results demonstrated that ISI and language experience both modulated behavioral performance, but only language experience, and not ISI, modulated the neural response. This is likely due to greater sensitivity of ERP measures to capture temporal dynamics contributing to the behavioral response.

Behavioral results were consistent with the previous literature on cross-linguistic speech perception (e.g., Werker and Logan, 1985; Levy and Strange, 2008). In addition, our hypothesis that language experience modulates the rate of memory trace decay was supported by the behavioral results. Specifically, the English listeners showed poorer discrimination and identification for the difficult /gypa/ vs. /gupa/ contrast and performance was the worst in the long ISI condition. In contrast, ISI did not affect the Mandarin listeners' behavioral performance.

For ERP results, larger MMNs were observed to the vowel contrasts for the Mandarin speakers than for the English speakers. This finding is consistent with the previous MMN literature on cross-language speech processing (e.g., Dehaene-Lambertz, 1997; Winkler et al., 1999a). We expected the language group difference to be greater for the /gypa/ than the /gipa/ deviant condition, but this interaction only approached significance. In addition, the MMN amplitude was generally larger for the /gypa/ condition than for the /gipa/ condition, but the LN was larger for the /gipa/ than the /gypa/ condition. We did not make specific predications regarding which speech sound contrast would show a greater difference for the Mandarin listeners, but we did expect English listeners to show a larger MMN to the /gipa/ than to the /gypa/ deviant, which we did not observe. P3a was generally larger in the native English speakers than in the Mandarin speakers. This finding supports that English listeners could detect the vowel difference. Finally, counter to our prediction, lengthening the ISI from half a second to $2.6 \mathrm{~s}$ for these vowel contrasts did not affect the MMN, P3a or LN amplitudes in either the English or the Mandarin listeners.
These findings are in contrast with the findings on lexical tone processing as reported in Yu et al. (2017). Below, we discuss these findings in greater detail.

\section{Behavioral Responses and Processing Levels}

Our behavioral discrimination results supported our hypotheses and were consistent with the previous literature. Specifically, in the long ISI conditions, listeners had to rely on their native phoneme categories for discriminating speech contrasts, and this resulted in poorer performance for English listeners on the vowel stimuli that were not contrastive in English (Pisoni, 1973; Werker and Tees, 1984; Werker and Logan, 1985; Burnham et al., 1996).

Previous studies using behavioral methods have proposed that speech perception may be influenced by several different factors, such as psychoacoustic auditory, language-general phonetic, and language-specific phonemic factors (Pisoni, 1973; Werker and Tees, 1984; Werker and Logan, 1985; Burnham et al., 1996) depending on the rate of sound presentation. Using an AX discrimination task, Werker and Logan (1985) found that when two stimuli were presented with an ISI of 250 and $500 \mathrm{~ms}$, American-English (AE) listeners were able to discriminate two different $\mathrm{CV}$ syllable tokens that were withincategory for English listeners (/d/), but across category (dental and retroflex stop consonants) for Hindi listeners. At a longer ISI of $1500 \mathrm{~ms}$, poor performance was observed for American (AE) listeners to the cross-category Hindi contrast. But Hindi listeners maintained good categorization performance. Werker and Logan (1985) interpreted these results as evidence of engaging three different levels of perception. They proposed that under conditions of high stimulus uncertainty and memory load, listeners rely on language-specific categories, while in less demanding task conditions (e.g., low memory demand) discrimination and categorization of speech information can be based on language-general phonetic properties. At the shortest ISIs, listeners can discriminate based on slight acoustic differences.

Our behavioral discrimination experiment differs slightly from the AX paradigms used by previous studies (Pisoni, 1973; Werker and Tees, 1984; Werker and Logan, 1985; Burnham et al., 1996). We adopted a modified version of our ERP oddball paradigm $\left(A_{1} A_{1} A_{2} A_{1} X\right.$ or $\left.A_{1} A_{2} A_{1} A_{1} X\right)$ for 
the purpose of examining correlations between behavioral and neurophysiological responses. Instead of using an ISI $500 \mathrm{~ms}$ vs. $1500 \mathrm{~ms}$, we used an SOA of $900 \mathrm{~ms}$ vs. $3000 \mathrm{~ms}$ (equivalent to ISI of about 575 and $2675 \mathrm{~ms}$, on average). Therefore, our long ISI condition was considerably longer than the ISI of $1500 \mathrm{~ms}$. The rationale for using a longer ISI was based on the result of our pilot studies for the ERP response to lexical tone.

It is possible that an ISI of $2675 \mathrm{~ms}$ was inadequate to observe a difference in the ERP responses, suggesting a dissociation between behavioral and neurophysiological measures under certain conditions. The alternative explanation is that the ISI of $575 \mathrm{~ms}$ (900 ms SOA) for the short condition was too long to engage acoustic-phonetic discrimination. The previous studies used simple consonant-vowel or vowel stimuli that were relatively short in duration (less than $300 \mathrm{~ms}$ ). The more complex stimuli in the current study were likely to increase the reliance on phonemic levels of processing (Strange, 2011). Thus, it is possible that a shorter ISI would result in a larger MMN for the English group (but no change for the Mandarin group). Irrespective of this possibility, our results reveal that the both native- and non-native-language groups maintained sufficient information to allow neural discrimination at the long ISI, but that this information did not support good behavioral perception of the /y/ vs. /u/ vowel for the English listeners.

In general, our behavioral discrimination results support the previous findings in that under long ISI conditions, listeners have to rely on their native phonemic categories for discriminating speech contrast. In our study, both the Mandarin and English listeners discriminated the /gipa-gupa/ contrast with similarly high accuracy under both short and long ISI conditions. However, for the /gypa-gupa/ contrast, the English listeners have lower accuracy in the short ISI condition, and more than $25 \%$ of the participants were at chance level in the long ISI condition. This pattern suggests that English listeners were able to use some language-general phonetic information for discrimination under the short ISI condition, but could not employ this information at the longer ISI, because the phonetic trace had decayed too much. Thus, the longer ISI condition reveals that English listeners have assimilated the / $/$ / vowel into the $/ \mathrm{u} /$ phonemic category. This finding was predicted and is consistent with Best's Perceptual Assimilation Model (Best, 1995; Best and Tyler, 2007).

Examination of the identification response patterns showed that /gipa/ tokens were only occasionally "mis"-labeled as "gupa" (4 and 15\% of total "non-gipa responses" for the Mandarin and English groups, respectively) by either language group, while labeling /gypa/ tokens as "gupa" accounted for $96 \%$ of total "non-gypa" responses for the English listeners; only $57 \%$ of the "non-gypa" responses were due to mislabeling/gypa/ tokens as "gupa" in the Mandarin listeners. So the behavioral identification result provide further evidence that American English listeners assimilate Mandarin /y/ to the English /u/ category. All the stimuli were produced by a native Mandarin speaker. The high discrimination and identification accuracy for /gipa/ and /gupa/ suggested that English listeners assimilated these Mandarin vowels into two difference English vowel categories, consistent with the two-category (TC) assimilation pattern in PAM (Best, 1995; Best and Tyler, 2007). Levy and Strange (2008) illustrated that vowel assimilation including the assimilation of frontrounded vowel /y/ into American English categories is dependent on context (i.e., preceding and following phonemes), task (passive vs. active listening, categorization vs. perceptual assimilation tasks) and listener factors (e.g., Levy and Strange, 2008; Strange et al., 2009).

\section{Duration of Auditory Memory for MMN, P3a, and LN}

An MMN to a pure tone deviant can be present under conditions with an ISI up to about 10-30 s, but the MMN was shown to reduce in amplitude as the ISI increased (Mäntysalo and Näätänen, 1987; Böttcher-Gandor and Ullsperger, 1992; Sams et al., 1993; Winkler and Cowan, 1996, 2005), especially in children and in the clinical population (see Bartha-Doering et al., 2015 for a review). These studies provided important data on the basic auditory sensory memory processing mechanism in humans. However, pure auditory tones differ from complex stimuli in a number of ways. In particular, the relevance of pure tone stimuli (when not part of a melody) is quite different from other complex auditory stimuli, such as speech. Our recent study on lexical tone revealed that differences in experience with speech information (native vs. non-native) modulate the time course of sensory memory decay for this information in the system as indexed by MMN (Yu et al., 2017). In the current study, we did not find evidence of ISI modulation in the MMN, P3a or LN amplitudes. Future studies need to examine memory trace decay of other types of complex (e.g., environmental sounds) and/or relevant auditory information (e.g., music) to determine whether the decay rate for well-learned speech categories is comparable to other well-learned auditory categories. In addition, it will be important to determine where the memory trace to the spectral information in vowels (in this case, primarily the first and second formants) decays much faster than for auditory tones, in that our "short" ISI may have been too long for the vowels in our study to observe the decay effect. In other words, the participants already needed to engage a phonological level of processing with an ISI of $575 \mathrm{~ms}$ for the natural speech in this study.

The fact that the MMN was present in all groups regardless of ISI and language background supported the earlier MMN literature on vowel processing (Aaltonen et al., 1987, 1994; Dehaene-Lambertz, 1997; Dehaene-Lambertz and Baillet, 1998; Sharma and Dorman, 1999, 2000; Winkler et al., 1999a,b; Shafer et al., 2004; Sussman et al., 2004; see Näätänen et al., 2007 for a review). It also expanded the current literature by showing that the MMN can be elicited for non-native vowels even when the ISI is greater than $2.5 \mathrm{~s}$. This is not the case for other speech categories such as lexical tone or consonant (Čeponiene et al., 1999; Yu et al., 2017). Using the same paradigm, we have found that the MMNs for a lexical tone contrast were absent in the English speaker groups when the ISI was long (Yu et al., 2017).

The absence of MMN amplitude attenuation in the long ISI conditions for either native or non-native vowel contrasts 
compared to the MMNs in the short ISI conditions suggests that the duration of auditory sensory memory for these non-native vowel contrasts is longer than that for non-native lexical tone contrast (at least for Mandarin tone 2 vs. 3). The alternative, is that auditory sensory memory to vowels is much shorter (and thus, the short and long ISI conditions in this study, both precluded acoustic-phonetic discrimination). Under either interpretation, our findings are consistent with recent behavioral findings that different types of speech are weighted differently in lexical access. The explanation that auditory sensory memory for vowels is longer than for lexical tone contrasts matches well with the findings that vowels are weighted more than consonants and lexical tone (Wiener and Turnbull, 2016).

The current study did not provide direct MMN evidence about the rate of sensory memory decay for vowel contrast, but it does show, for the first time, that the sensory memory for a vowel contrast lasts longer than $2.6 \mathrm{~s}$; this is longer than the $2 \mathrm{~s}$ reported for consonants in 7- to 9-year old children with good phonological memory skills, and also longer than that reported for lexical tone in non-native speakers. Future studies should use both longer and shorter ISIs to examine if and how ISI influences the amplitude of MMN for vowel contrast.

The question of whether and how the P3a response changes as a function of ISI has rarely been examined. Friedman et al. (2001) proposed that the P3a is "associated more with the evaluation" of detected deviant events "for subsequent behavioral action." The findings in this study suggest that this evaluation process, following deviance detection, is not influenced by an ISI difference of $2 \mathrm{~s}$ for vowels.

We predicted that P3a amplitude would be smaller under more challenging conditions such as when the magnitude of stimulus deviance is small (e.g., the /gypa/ deviant condition) or when memory decay is greater (e.g., the long ISI condition). However, we did not see evidence of ISI modulation of P3a, nor evidence of a stimulus deviance effect. Instead, we saw an effect of language experience. That is, the English listeners had larger P3a than the Mandarin listeners, suggesting that the English listeners automatically oriented to the deviance more. This finding is consistent with the literature, which has observed larger P3a amplitude for non-native contrasts and for laterlearned contrasts (Shestakova et al., 2003; Ortiz-Mantilla et al., 2010). We re-examined the P3a data from the lexical tone study in $\mathrm{Yu}$ et al. (2017), which revealed that P3a was also larger in the English groups than the Mandarin groups to lexical tone contrasts. The larger P3a amplitude in the English listeners to the Mandarin or less-prototypical English contrasts may indeed reflect an increased level of "perceptual vigilance," as suggested by Ortiz-Mantilla et al. (2010). It is possible that the less nativelike deviant is not as predictable as the native deviance, especially in a multiple deviance paradigm, since fully predictable deviance leads to absence of P3a and LN (Ritter et al., 1999; Sussman et al., 2003).

We did not find clear evidence that ISI affected the LN amplitude. The LN amplitude differed under the two deviant conditions, with larger LN for the /gipa/ deviant than for the /gypa/ deviant condition. This is the opposite pattern to the $\mathrm{MMN}$ responses. As discussed above, the MMN amplitude was larger in the /gypa/ than the /gipa/ deviant condition. The phonetic-phonological properties of $/ \mathrm{y} /, \mathrm{i} / \mathrm{h}$, and $/ \mathrm{u} /$ support a greater difference between $/ \mathrm{i} /$ an $/ \mathrm{u} /$ than between $/ \mathrm{y} /$ and $/ \mathrm{u} /$ because the $/ \mathrm{i} /$ differs from $/ \mathrm{u} /$ in both the back and round feature, whereas / $y /$ only differs in the back feature. Several studies of language/learning differences have found reduced MMN and comparable or larger LN in the less proficient language groups (e.g., family history of language impairment: Addis et al., 2010; children with SLI: Shafer et al., 2005; second language learners: Ortiz-Mantilla et al., 2010). Some studies also found the opposite with smaller LN in the less proficient language users/learners (Barry et al., 2009; Bishop et al., 2010). Therefore, the nature of LN still requires explanation. It seems that, at this time, more evidence supports the account that the LN reflects additional recruitment of cognitive resources for further processing of the sound contrast, as it can be generated independently of the amplitude of MMN. Across studies, LN is sometimes absent when MMN is robust, especially when the task is easy, such as in this study. $\mathrm{LN}$ was present but very small in the short ISI /gypa/ condition, in which large MMNs were present.

One neuronal network operation principle is to minimize the cost (Bullmore and Sporns, 2012). Based on this principle, it is feasible to propose that MMN and LN represent a twostage sequential process. If the processing is sufficient and adequately automatic during the early processing time window as indexed by a robust $\mathrm{MMN}$, then no further processing is necessary, thus no LN will be elicited. For a difficult vowel contrast or challenging perceptual condition, the early automatic discrimination may or may not take place, and LN represents the recruitment of additional resources. We do not see a clear association between $\mathrm{P} 3 \mathrm{a}$ and $\mathrm{LN}$ amplitude. However, we did not design our study to examine the association/disassociation of MMN, P3a and LN. The earlier three-stage sequential model (MMN-P3a-LN, or MMN-P3a-RON) was proposed by Escera and Corral $(2003,2007)$ and other colleagues. Our study supports the pair-wise dissociation of the three ERP components suggested by Horváth et al. (2008b). The rate of sensory memory decay does not change the pair-wise dissociation of MMN, P3a and LN amplitude.

\section{The Dissociation Between Behavioral and Neurophysiological Responses}

In the behavioral literature, an ISI of $1500 \mathrm{~ms}$ was adequate to lead to lower discrimination accuracy to consonant contrasts; however, in the ERP literature, the MMN amplitude to a pure tone contrast can be robust even when the ISI was beyond $10 \mathrm{~s}$. We were interested in whether the linguistic nature of the stimuli would make a difference to the ISI modulation effect. In the lexical tone study, we found that an ISI of $2.5 \mathrm{~s}$ led to MMN and LN absence/reduction and lower behavioral discrimination accuracy. However, in this study of vowel deviance, we found a dissociation between the behavioral discrimination accuracy and neurophysiological responses. Our findings for behavioral discrimination support the prediction that a longer ISI leads to more reliance on phonemic-level 
processing. In contrast, the lack of an ISI effect on the MMN, $\mathrm{P} 3 \mathrm{a}$, and LN amplitude for either language group suggests that phonetic level information is still available for vowel contrasts up to an ISI of $2.5 \mathrm{~s}$. The dissociation between behavioral and neural measures has been reported previously (e.g., Shafer et al., 2005). Discrimination accuracy rate can be influenced by many other factors such as focused attention, inhibition, and working memory that are less apparent in the passive listening paradigm. The association and dissociation between behavioral and neural measures needs to be further examined more systematically in future studies.

\section{Vowel vs. Lexical Tone Processing}

Overall, we found that the neural responses to the vowel contrasts differed from the lexical tone contrasts, although the behavioral pattern of responses to the vowel contrasts were very similar to that of the lexical tone contrast. These neural discrimination differences may indicate functional and origin variations at the cortex level (e.g., Shestakova et al., 2004; Bouchard and Chang, 2014).

We have evidence of 'tonotopic' maps in the auditory cortex from early MEG studies (Romani et al., 1982; Pantev et al., 1988; Shestakova et al., 2004; Talavage et al., 2004). As shown in Shestakova et al. (2004), the amplitudes and source location of N1 differs for different vowel (e.g., Russian vowels [a], [i], and [u] used in the study), and vowels with more dissimilar spectral envelopes are more distantly coded at the cortex level. Recent electrocorticographic recordings suggested that the ventral sensory-motor cortex (vSMC) is the origin of neural activity that exerts precise vocal tract movements (Bouchard and Chang, 2014). The same research group has also reported that posterior superior temporal gyri (pSTG) serve as a critical locus for voice-onset time in consonant production (Chang et al., 2010). The majority of human imaging studies suggested that the lateral end of Heschl's sulcus, anterolateral to primary auditory cortex, is the center for processing fundamental frequency (Patterson et al., 2002; Penagos et al., 2004; Wang, 2013). Thus, ERP differences among vowel, consonant and lexical tone units could reflect different neural origins and functions at the cortical level. It is possible that differences in sensory memory decay effects for lexical tone vs. vowel contrast (/gypa/-/gupa/) is related to these functional differences. However, this difference could be due to acoustic salience. It is challenging to equate acoustic difference across different acoustic properties (e.g., stimulus duration, fundamental frequency, spectral information in formants), which complicates explaining these differences. Future studies that manipulate the degree of difference within and across these properties are necessary to fully understand how these relate to neural discrimination and behavior.

\section{Stimulus Variable and the MMN Latency of /gipa/ Deviant}

Many cross-language studies have used synthetic speech to allow strict control over the variance of acoustic parameters. However, natural speech produced by human speakers is quite variable, and the multiple acoustic parameters that are exploited by native listeners to differentiate the phonemic categories are still not entirely understood. The perceptual patterns observed for highly controlled synthetic speech may not reflect the reality of everyday speech perception. Thus, a more ecologically valid task, as promoted by Strange and Shafer (2008), is the use of natural speech. In the current study, we used two tokens per deviant category, and three tokens for the standard category of naturally produced bisyllabic non-words. These tokens were selected from a large pool of recordings based on careful listening and detailed acoustic analysis of voice onset time for $/ g /$ and $/ \mathrm{p} /$, vowel onset and offset time, vowel formant frequencies, F0 contour, overall amplitude and duration, duration and amplitude of each segment within the syllable, and to ensure that phonetically irrelevant acoustic variability was not highly correlated with the phonetically relevant acoustic variability, but to allow for the natural variability found in everyday speech. The syllable durations for the two tokens of /gi/ were approximately 20-25 ms shorter than those of $/ \mathrm{gu} /$, and the syllable duration for one token of /gy/ was approximately $18 \mathrm{~ms}$ longer than those of /gu/. The coarticulatory cues in the voicing (which was prevoicing) would allow differences of the deviant stimuli to be calculated from stimulus onset. Thus, the earlier MMN to the /gi/ syllable compared to /gy/ syllable cannot be explained by the differences in syllable duration. It is possible that a later MMN, related to syllable duration differences could add into the MMN amplitude. However, it is important to recognize that our goal was not to specifically compare the difficultly of neural discrimination of $/ \mathrm{i} /$ and $/ \mathrm{y} /$ from /u/. Rather it was to determine the effects of language experience and shortterm memory decay on neural discrimination of highly natural vowels.

By implementing such natural speech, we hoped to tap into phonemic processing to a greater extent than found in processing synthetic speech without introducing so much variability that the "noise" masked the contrast of interest. The behavioral responses indicate that use of natural speech is adequate. Both deviant types /gi/ and /gy/ are illegal syllables in Mandarin (/gu/, /ga/, and /ge/ are allowed), and /gipa/, /gypa/, and /gupa/ are all nonwords in both Mandarin and English. Therefore, phonotactic probabilities (biphone probability) were similar for the two language groups.

One unexpected finding was the latency of the MMN for /gipa/ deviant appears to peak quite early at around $100 \mathrm{~ms}$, but its amplitude is smaller than that of /gypa/ regardless of ISI and language groups. It is established that an easy contrast will lead to earlier MMN latency. The acoustic difference in terms of all the parameters mentioned in the paragraph above for /gipa/ and /gypa/ are quite subtle except for in F2 and F3. For these values, /gipa/ is acoustically more distinct than /gypa/ from /gupa/, in part due to the round-feature difference. This greater difference is consistent with an earlier MMN. Separating the behavioral and ERP data by deviant tokens suggests that one token of /gipa/ (Token 2 in Table 1) was identified with lower overall accuracy (75\% for Token 2 vs. 95\% for Token 1) than the other token by the 32 Mandarin listeners, and the MMN for this token was later in the Mandarin short ISI group. This may partly account for the 
two peaks for /gipa/ and the one for the /gypa/ deviant. Regardless of the explanation, our main interest was in the group difference. The fact that both groups showed these patterns, suggest that the acoustic-phonetic level of processing is the source of this difference.

\section{CONCLUSION}

To our knowledge, this is the first neurophysiological study examining the role of long-term memory representations for vowel processing. We found that behavioral discrimination accuracy was reduced in the long ISI compared to shortISI condition for non-native vowel deviance. In contrast, no amplitude differences were observed for MMN, P3a, and LN between the short- and long-ISI memory trace decay conditions. For both ISIs, MMN was elicited, and it was larger for the Mandarin than English group, particularly for the difficult Mandarin contrast. This finding suggested that echoic sensory memory trace maintenance for vowels differs from that for lexical tone (fundamental frequency). Our future goals are to evaluate specific hypotheses concerning mechanisms underlying MMN dysfunction in memory disorders such as schizophrenia, children with

\section{REFERENCES}

Aaltonen, O., Eerola, O., Lang, A. H., and Uusipaikka, E. (1994). Automatic discrimination of phonetically relevant and irrelevant vowel parameters as reflected by mismatch negativity. J. Acoust. Soc. Am. 96, 1489-1493. doi: 10.1121/1.410291

Aaltonen, O., Niemi, P., Nyrke, T., and Tuhkanen, M. (1987). Event-related brain potentials and the perception of a phonetic continuum. Biol. Psychol. 24, 197-207. doi: 10.1016/0301-0511(87)90002-0

Addis, L., Friederici, A. D., Kotz, S. A., Sabisch, B., Barry, J., Richter, N., et al. (2010). A locus for an auditory processing deficit and language impairment in an extended pedigree maps to 12p13.31-q14.3. Genes Brain Behav. 9, 545-561. doi: 10.1111/j.1601-183X.2010.00583.x

Amenedo, E., and Escera, C. (2000). The accuracy of sound duration representation in the human brain determines the accuracy of behavioral perception. Eur. J. Neurosci. 12, 2570-2574. doi: 10.1046/j.1460-9568.2000.00114.x

Barry, J. G., Hardiman, M. J., and Bishop, D. V. (2009). Mismatch response to polysyllabic nonwords: a neurophysiological signature of language learning capacity. PLoS One 4:e6270. doi: 10.1371/journal.pone.000 6270

Barry, J. G., Hardiman, M. J., Line, E., White, K. B., Yasin, I., and Bishop, D. V. (2008). Duration of auditory sensory memory in parents of children with SLI: a mismatch negativity study. Brain Lang. 104, 75-88. doi: 10.1016/j.bandl.2007. 02.006

Bartha-Doering, L., Deuster, D., Giordano, V., am Zehnhoff-Dinnesen, A., and Dobel, C. (2015). A systematic review of the mismatch negativity as an index for auditory sensory memory: from basic research to clinical and developmental perspectives: MMN as an index for auditory sensory memory. Psychophysiology 52, 1115-1130. doi: 10.1111/psyp.12459

Best, C. T., and Tyler, M. C. (2007). "Nonnative and second-language speech perception: commonalities and complementarities," in Language Experience in Second Language Speech Learning: In Honor of James Emil Flege, eds O. S. Bohn, and M. J. Munro (Amsterdam: John Benjamins), 13-34. doi: 10.1075/lllt.17. 07bes

Best, C. T. (1995). "A direct realist perspective on cross-language speech perception," in Speech Perception and Linguistic Experience: Issues in Cross-Language Research, ed. W. Strange (Timonium, MD: York Press), 171-204. phonological working memory deficit, or low language proficiency.

\section{AUTHOR CONTRIBUTIONS}

YY and VS: developed the paradigm. YY, VS, and ES: data analysis, manuscript writing.

\section{FUNDING}

This project was funded by Rees Dissertation Fellowship to YY at the Graduate Center, City University of New York. This project was also funded by the National Institutes of Health (\#HD46193 to VS and \#DC004263 to ES).

\section{ACKNOWLEDGMENTS}

We would like to thank Winifred Strange and Richard G. Schwartz for their advice on the design. We also would like to thank D. H. Whalen for his insightful comments on an earlier draft of this manuscript.

Bishop, D. V., Hardiman, M. J., and Barry, J. G. (2010). Lower-frequency eventrelated desynchroization: a signature of late mismatch responses to sounds, which is reduced or absent in children with specific language impairment. J. Neurosci. 30, 15578-15584. doi: 10.1523/JNEUROSCI.2217-10.2010

Boersma, P. (2001). Praat, a system for doing phonetics by computer. Glot Int. 5, 341-345.

Böttcher-Gandor, C., and Ullsperger, P. (1992). Mismatch negativity in eventrelated potentials to auditory stimuli as a function of varying interstimulus interval. Psychophysiology 29, 546-550. doi: 10.1111/j.1469-8986.1992. tb02028.x

Bouchard, K. E., and Chang, E. F. (2014). Control of spoken vowel acoustics and the influence of phonetic context in human speech sensorimotor cortex. J. Neurosci. 34, 12662-12677. doi: 10.1523/JNEUROSCI.1219-14.2014.

Bullmore, E., and Sporns, O. (2012). The economy of brain network organization. Nat. Rev. Neurosci. 13, 336-349. doi: 10.1038/nrn3214

Burnham, D., Francis, E., Webster, D., Luksaneeyanawin, S., Attapaiboon, C., Lacerda, F., et al. (1996). "Perception of lexical tone across languages: evidence for a linguistic mode of processing," in Proceedings the 4th International Conference on Spoken Language Processing (ICSLP 96), 4, Philadelphia, PA, 2514-2517.

Čeponienè, R., Cheour, M., and Näätänen, R. (1998). Interstimulus interval and auditory event-related potentials in children: evidence for multiple generators. Electroencephalogr. Clin. Neurophysiol. 108, 345-354.

Čeponienè, R., Service, E., Kurjenluoma, S., Cheour, M., and Näätänen, R. (1999). Children's performance on pseudoword repetition depends on auditory trace quality: evidence from event-related potentials. Dev. Psychol. 35, 709-720.

Chang, E. F., Rieger, J. W., Johnson, K., Berger, M S., Barbaro, N. M., Knight, R. T. (2010). Categorical speech representation in human superior temporal gyrus. Nat. Neurosci. 13, 1428-1432. doi: 10.1038/nn.2641

Choudhury, N. A., Parascando, J. A., and Benasich, A. A. (2015). Effects of presentation rate and attention on auditory discrimination: a comparison of long-latency auditory evoked potentials in school-aged children and adults. PLoS One 10:e0138160. doi: 10.1371/journal.pone.0138160

Cowan, N. (1984). On short and long auditory stores. Psychol. Bull. 96, 341-370. doi: 10.1037/0033-2909.96.2.341

Cowan, N. (1988). Evolving conceptions of memory storage, selective attention, and their mutual constraints within the human information-processing system. Psychol. Bull. 104, 163-191. doi: 10.1037/0033-2909.104.2.163 
Czigler, I., Csibra, G., and Csontos, A. (1992). Age and inter-stimulus interval effects on event-related potentials to frequent and infrequent auditory stimuli. Biol. Psychol. 33, 195-206. doi: 10.1016/0301-0511(92)90031-O

Datta, H., Shafer, V. L., Morr, M. L., Kurtzberg, D., and Schwartz, R. G. (2010). Electrophysiological indices of discrimination of long-duration, phonetically similar vowels in children with typical and atypical language development. J. Speech Hear. Res. 53, 757-777. doi: 10.1044/1092-4388(2009/08-0123)

Dehaene-Lambertz, G. (1997). Electrophysiological correlates of categorical phoneme perception in adults. Neuroreport 8, 919-924. doi: 10.1097/00001756199703030-00021

Dehaene-Lambertz, G., and Baillet, S. (1998). A phonological representation in the infant brain. Neuroreport 9, 1885-1888. doi: 10.1097/00001756-19980601000040

Escera, C., Alho, K., Schröger, E., and Winkler, I. (2000). Involuntary attention and distractibility as evaluated with event-related brain potentials. Audiol. Neuro Otol. 5, 151-166. doi: 10.1159/000013877

Escera, C., Alho, K., Winkler, I., and Näätänen, R. (1998). Neural mechanisms of involuntary attention to acoustic novelty and change. J. Cogn. Neurosci. 10, 590-604. doi: 10.1162/089892998562997

Escera, C., and Corral, M. -J. (2003). "The distraction potential (DP), an electrophysiological tracer of involuntary attention control and its dysfunction," in The Cognitive Neuroscience of Individual Differences, eds I. Reinvang, M. W. Greenlee, and M. Hermann (Oldenburg: Bibliotheks-und Informationsystem des Universität Oldenburg), 63-76.

Escera, C., and Corral, M. J. (2007). Role of mismatch negativity and novelty-P3 in involuntary auditory attention. J. Psychophysiol. 21, 251-264. doi: 10.1027/ 0269-8803.21.34.251

Escera, C., Yago, E., and Alho, K. (2001). Electrical responses reveal the temporal dynamics of brain events during involuntary attention switching. Eur. J. Neurosci. 14, 877-883. doi: 10.1046/j.0953-816x.2001.01707.x

Friedman, D., Cycowicz, Y. M., and Gaeta, H. (2001). The novelty P3: an eventrelated brain potential (ERP) sign of the brain's evaluation of novelty. Neurosci. Biobehav. Rev. 25, 355-373. doi: 10.1016/S0149-7634(01)00019-7

Gomes, H., Sussman, E., Ritter, W., Kurtzberg, D., Cowan, N., and Vaughan, H. G. Jr. (1999). Electrophysiological evidence of developmental changes in the duration of auditory sensory memory. Dev. Psychol. 35, 294-302. doi: 10.1037/ 0012-1649.35.1.294

Hao, Y. C. (2017). Second language perception of mandarin vowels and tones. Lang. Speech. doi: 10.1177/0023830917717759 [Epub ahead of print].

Horváth, J., Czigler, I., Jacobsen, T., Maess, B., Schröger, E., and Winkler, I. (2008a). MMN or no MMN: no magnitude of deviance effect on the MMN amplitude. Psychophysiology 45, 60-69.

Horváth, J., Winkler, I., and Bendixen, A. (2008b). Do N1/MMN, P3a, and RON form a strongly coupled chain reflecting the three stages of auditory distraction? Biol. Psychol. 79, 139-147. doi: 10.1016/j.biopsycho.2008.04.001

Howie, J. M. (1976). Acoustical Studies of Mandarin Vowels and Tones. Cambridge: Cambridge University Press.

Igor Pro (2017). Wavemetrics. Available at: http://www.wavemetrics.com

Imada, T., Hari, R., Loveless, N., McEvoy, L., and Sams, M. (1993). Determinants of the auditory mismatch response. Electroencephalogr. Clin. Neurophysiol. 87, 144-153. doi: 10.1016/0013-4694(93)90120-K

Javitt, D. C., Grochowski, S., Shelley, A. M., and Ritter, W. (1998). Impaired mismatch negativity (MMN) generation in schizophrenia as a function of stimulus deviance, probability, and interstimulus/interdeviant interval. Electroencephalogr. Clin. Neurophysiol. 108, 143-153.

Kaan, E., Wayland, R., Bao, M., and Barkley, C. M. (2007). Effects of native language and training on lexical tone perception : an event-related potential study. Brain Res. 1148, 113-122. doi: 10.1016/j.brainres.2007.02.019

Korpilahti, P., Krause, C. M., Holopainen, I., and Lang, A. H. (2001). Early and late mismatch negativity elicited by words and speech-like stimuli in children. Brain Lang. 76, 332-339. doi: 10.1006/brln.2000.2426

Lang, H.A., Nyrke, T., Ek, M., Aaltonen O, Raimo I, \& Näätänen R. (1990). "Pitch discrimination performance and auditory event-related potentials," in Psychophysiological Brain Research, Vol. 1, eds C. H. M. Brunia, A. W. K. Gaillard, A. Kok, G. Mulder, and M. N. Verbaten, (Tilburg: Tilburg University Press), 294-298.

Lee, W.-S., and Zee, E. (2003). Standard Chinese (Beijing). J. Int. Phon. Assoc. 33, 109-112. doi: 10.1017/S0025100303001208
Levy, E. S., and Strange, W. (2008). Perception of French vowels by American English adults with and without French language. J. Phon. 36, 141-157. doi: 10.1016/j.wocn.2007.03.001

Mäntysalo, S., and Näätänen, R. (1987). The duration of a neuronal trace of an auditory stimulus as indicated by event-related potentials. Biol. Psychol. 24, 183-195. doi: 10.1016/0301-0511(87)90001-9

Näätänen, R., Gaillard, A.W., Mäntysalo, S. (1978). Early selective-attention effect on evoked potential reinterpreted. Acta Psychol. 42, 313-329. doi: 10.1016/ 0001-6918(78)90006-9

Näätänen, R., Lehtokoski, A., Lennes, M., Cheour, M., Huotilainen, M., Iivonen, A., et al. (1997). Language-specific phoneme representations revealed by electric and magnetic brain responses. Nature 385, 432-434. doi: 10.1038/385432a0

Näätänen, R., Paavilainen, P., Rinne, T., and Alho, K. (2007). The mismatch negativity $(\mathrm{MMN})$ in basic research of central auditory processing: a review. Clin. Neurophysiol. Neurophysiol. 118, 2544-2590. doi: 10.1016/j.clinph.2007. 04.026

Näätänen, R., Kujala, T., and Winkler, I. (2011). Auditory processing that leads to conscious perception: a unique window to central auditory processing opened by the mismatch negativity and related responses. Psychophysiology 48, 4-22. doi: 10.1111/j.1469-8986.2010.01114.x.

Olejnik, S., and Algina, J. (2003). Generalized Eta and Omega squared statistics: measures of effect size for some common research designs. Psychol. Methods 8, 434-447. doi: 10.1037/1082-989X.8.4.434

Ortiz-Mantilla, S., Choudhury, N., Alvarez, B., and Benasich, A. A. (2010). Involuntary switching of attention mediates differences in event-related responses to complex tones between early and late Spanish-English bilinguals. Brain Res. 1362, 78-92. doi: 10.1016/j.brainres.2010.09.031

Pantev, C., Hoke, M., Lehnertz, K., Lütkenhöner, B., Anogianakis, G., and Wittkowski, W. (1988). Tonotopic organization of the human auditory cortex revealed by transient auditory evoked magnetic fields. Electroencephalogr. Clin. Neurophysiol. 69, 160-170. doi: 10.1016/0013-4694(88) 90211-8

Patterson, R. D., Uppenkamp, S., Johnsrude, I. S., and Griffiths, T. D. (2002). The processing of temporal pitch and melody information in auditory cortex. Neuron 36, 767-776. doi: 10.1016/s0896-6273(02)01060-7

Penagos, H., Melcher, J. R., and Oxenham, A. J. (2004). A neural representation of pitch salience in nonprimary human auditory cortex revealed with functional magnetic resonance imaging. J. Neurosci. 24, 6810-6815. doi: 10.1523/JNEUROSCI.0383-04.2004

Pinheiro, J., Bates, D., DebRoy, S., Sarkar, D., and R Core Team (2017). nlme: Linear and Nonlinear Mixed Effects Models. R Package Version 3.1-131. Available at: https://CRAN.R-project.org/package=nlme

Pisoni, D. B. (1973). Auditory and phonetic memory codes in the discrimination of consonants and vowels. Percept. Psychophys. 13, 253-260. doi: 10.3758/ BF03214136

Polich, J. (1988). Bifurcated P300 peaks: P3a and P3b revisited? J. Clin. Neurophysiol. 5, 287-294. doi: 10.1097/00004691-198807000-00004

Polich, J. (2007). Updating P300: an integrative theory of P3a and P3b. Clin. Neurophysiol. 118, 2128-2148. doi: 10.1016/j.clinph.2007.04.019

R Core Team (2016). R: A Language and Environment for Statistical Computing. Vienna: R Foundation for Statistical Computing.

Rinne, T., Särkkä, A., Degerman, A, Schröger, E., and Alho, K. (2006). Two separate mechanisms underlie auditory change detection and involuntary control of attention. Brain Res. 1077, 135-143. doi: 10.1016/j.brainres.2006.01.043

Ritter, W., Sussman, E., Deacon, D., Cowan, N., and Vaughan, H. G. (1999). Two cognitive systems simultaneously prepared for opposite events. Psychophysiology 36, 835-838. doi: 10.1111/1469-8986.3660835

Romani G. L., Williamson S. J., and Kaufman L. (1982). Tonotopic organization of the human auditory cortex. Science 216, 1339-1340. doi: 10.1126/science. 7079770

RStudio Team (2016). RStudio: Integrated Development for R. Boston, MA: RStudio Inc.

Sams, M., Ahlo, K., and Näätänen, R. (1983). Sequential effects on the ERP in discriminating two stimuli. Biol. Psychol. 17, 41-58. doi: 10.1016/0301-0511(83) 90065-0

Sams, M., Hari, R., Rif, J., and Knuutila, J. (1993). The human auditory sensory trace persists about 10 seconds: neuromagnetic evidence. J. Cogn. Sci. 5, $363-370$. 
Sams, M., Paavilainen, P., Alho, K., and Näätänen, R. (1985). Auditory frequency discrimination and event-related potentials. Electroencephalogr. Clin. Neurophysiol. 62, 437-448.

Schröger, E. (1996). A neural mechanism for involuntary attention shifts to changes in auditory stimulation. J. Cogn. Neurosci. 8, 527-539. doi: 10.1162/jocn.1996.8. 6.527

Schröger, E., and Wolff, C. (1998a). Attentional orienting and reorienting is indicated by human event-related brain potentials. Neuroreport 9, 3355-3358.

Schröger, E., and Wolff, C. (1998b). Behavioral and electrophysiological effects of task-irrelevant sound change: a new distraction paradigm. Brain Res. Cogn. Brain Res. 7, 71-87.

Shafer, V. L., Morr, M. L., Datta, H., Kurtzberg, D., and Schwartz, R. G. (2005). Neurophysiological indexes of speech processing deficits in children with specific language impairment. J. Cogn. Neurosci. 17, 1168-1180. doi: 10.1162/ 0898929054475217

Shafer, V. L., Schwartz, R. G., and Kurtzberg, D. (2004). Language-specific memory traces of consonants in the brain. Brain Res. Cogn. Brain Res. 18, 242-254. doi: 10.1016/j.cogbrainres.2003.10.007

Sharma, A., and Dorman, M. F. (1999). Cortical auditory evoked potential correlates of categorical perception of voice-onset time. J. Acoust. Soc. Am. 106, 1078-1083. doi: 10.1121/1.428048

Sharma, A., and Dorman, M. F. (2000). Neurophysiologic correlates of crosslanguage phonetic perception. J. Acoust. Soc. Am. 107, 2697-2703. doi: 10.1121/ 1.428655

Shestakova, A., Brattico, E., Soloviev, A., Klucharev, V., and Huotilainen, M. (2004). Orderly cortical representation of vowel categories presented by multiple exemplars. Cogn. Brain Res. 21, 342-350 doi: 10.1016/j.cogbrainres.2004. 06.011

Shestakova, A., Huotilainen, M., Čeponienè, R., and Cheour, M. (2003). Eventrelated potentials associated with second language learning in children. Clin. Neurophysiol. 114, 1507-1512. doi: 10.1016/S1388-2457(03)00134-2

Squires, N. K., Squires, K. C., and Hillyard, S. A. (1975). Two varieties of long-latency positive waves evoked by unpredictable auditory stimuli in man. Electroencephalogr. Clin. Neurophysiol. 38, 387-401. doi: 10.1016/00134694(75)90263-1

Strange, W. (2011). Automatic selective perception (ASP) of first and second language speech: a working model. J. Phon. 39, 456-466. doi: 10.1016/j.wocn. 2010.09.001

Strange, W., Levy, E. S., and Law, F. F. (2009). Cross-language categorization of French and German vowels by naïve American listeners. J. Acoust. Soc. Am. 126, 1461-1476. doi: 10.1121/1.3179666

Strange, W., and Shafer, V. (2008). "Speech perception in second language learners: the re-education of selective perception," in Phonology and Second Language Acquisition, eds G. J. Hansen Edwards, and M. L. Zampini (John Benjamins, Amsterdam), 153-191.

Sussman, E., Kujula, T., Halmetoja, J., Lyytinen, H., Alku, P., and Näätänen, R. (2004). Automatic and controlled processing of acoustic and phonetic contrasts. Hear. Res. 190, 128-140. doi: 10.1016/S0378-5955(04)00016-4

Sussman, E., Winkler, I., and Schröger, E. (2003). Top-down control over involuntary attention switching in the auditory modality. Psychon. Bull. Rev. 10, 630-637 doi: 10.3758/BF03196525

Sussman, E. S., Steinschneider, M., Gumenyuk, V., Grushko, J., and Lawson, K. (2008). The maturation of human evoked brain potentials to sounds presented at different stimulus rates. Hear. Res. 236, 61-79. doi: 10.1016/j.heares.2007. 12.001
Talavage, T. M., Sereno, M. I., Melcher, J. R., Ledden, P. J., Rosen, B. R., and Dale, A. M. (2004). Tonotopic organization in human auditory cortex revealed by progressions of frequency sensitivity. J. Neurophysiol. 91, 1282-1296. doi: $10.1152 /$ jn. 01125.2002

Tiitinen, H., Sinkkonen, J., May, P., and Näätänen, R. (1994). The auditory transient $40-\mathrm{Hz}$ response is insensitive to changes in stimulus features. Neuroreport 6, 190-192. doi: 10.1097/00001756-19941230000048

Wang, X. (2013). The harmonic organization of auditory cortex. Front. Syst. Neurosci. 7:114. doi: 10.3389/fnsys.2013.00114

Werker, J. F., and Logan, J. S. (1985). Cross-language evidence for three factors in speech perception. Percept. Psychophys. 37, 35-44. doi: 10.3758/BF03207136

Werker, J. F., and Tees, R. C. (1984). Phonemic and phonetic factors in adult crosslanguage speech perception. J. Acoust. Soc. Am. 75, 1866-1878. doi: 10.1121/1. 390988

Wiener, S., and Turnbull, R. (2016). Constraints of tones, vowels and consonants on lexical selection in Mandarin Chinese. Lang. Speech 59, 59-82. doi: 10.1177/ 0023830915578000

Winkler, I., and Cowan, N. (1996). Interactions between transient and long-term auditory memory as reflected by the mismatch. J. Cogn. Neurosci. 8, 403-415. doi: 10.1162/jocn.1996.8.5.403

Winkler, I., and Cowan, N. (2005). From sensory to long-term memory: evidence from auditory memory reactivation studies. Exp. Psychol. 52, 3-20. doi: 10.1027/ 1618-3169.52.1.3

Winkler, I., Lehtokoski, A., Alku, P., Vainio, M. Czigler, I., Csépe, V., Aaltonen, O. Raimo, I., et al. (1999a). Pre-attentive detection of vowel contrasts utilizes both phonetic and auditory memory representations. Brain Res. Cogn. Brain Res. 7, 357-369.

Winkler, I., Kujala, T., Tiitinen, H., Sivonen, P., Alku, P., Lehtokoski, A., et al. (1999b). Brain responses reveal the learning of foreign language phonemes. Psychophysiology 36, 638-642.

Winkler, I., Tervaniemi, M., Schröger, E., Wolff, C., and Näätänen, R. (1998). Preattentive processing of auditory spatial information in humans. Neurosci. Lett. 242, 49-52. doi: 10.1016/S0304-3940(98)00022-6

Yago, E., Corral, M. J., and Escera, C. (2001). Activation of brain mechanisms of attention switching as a function of auditory frequency change. Neuroreport 12 , 4093-4097. doi: 10.1097/00001756-200112210-00046

Yu, Y. H., Shafer, V. L., and Sussman, E. S. (2017). Neurophysiological and behavioral responses of mandarin lexical tone processing. Front. Neurosci. 11:95. doi: 10.3389/fnins.2017.00095

Zevin, J. D., Datta, H., Maurer, U., Rosania, K. A., and McCandliss, B. D. (2010). Native language experience influences the topography of the mismatch negativity to speech. Front. Hum. Neurosci. 4:212. doi: 10.3389/fnhum.2010. 00212

Conflict of Interest Statement: The authors declare that the research was conducted in the absence of any commercial or financial relationships that could be construed as a potential conflict of interest.

Copyright (c) $2018 \mathrm{Yu}$, Shafer and Sussman. This is an open-access article distributed under the terms of the Creative Commons Attribution License (CC BY). The use, distribution or reproduction in other forums is permitted, provided the original author(s) and the copyright owner are credited and that the original publication in this journal is cited, in accordance with accepted academic practice. No use, distribution or reproduction is permitted which does not comply with these terms. 